\title{
Design and Manufacturing of Bunk Bed with Leisure Sofa
}

\author{
Kunal Tekade \\ Dept of Mechanical Engineering \\ SSGMCE, Shegaon \\ Jayesh Tale \\ Dept of Mechanical Engineering \\ SSGMCE, Shegaon
}

\author{
Ajay Chawale \\ Dept of Mechanical Engineering \\ SSGMCE, Shegaon \\ Pranav Chandurkar \\ Dept of Mechanical Engineering \\ SSGMCE, Shegaon
}

\author{
Dr. Nilesh Khandare \\ (Assistant Professor) \\ Dept of Mechanical Engineering \\ SSGMCE, Shegaon
}

\begin{abstract}
In India majority of Indian middle class populations are living in small flats and homes this is Mostly because of their economy scale as well as the lack of space availability for living. But in the present Scenario furniture occupies a majority of the space in the home. Moreover, high population density leads Many other problems such as high gap between rich and poor, high energy cost and house price. These are common problem in now days. Space saving furniture is one of the options to solve these problems
\end{abstract}

In this paper, we will introduce you with BUNK BED with LEISURE SOFA with for proper utilization of space without sacrificing comfort.

Keywords: Bunk bed, sofa, low cost, furniture

\section{INTRODUCTION}

Seating arrangements, chairs \& furniture's were earliest inventions of man. A space saving bunk bed with leisure sofa designed especially for middle class persons as well as living in small flats and homes this is mostly because of their economy scale and lack of space availability for living, along with it can found useful to railway station, airport for passenger waiting in the terminal. It can also be useful to the workers who works in shifts. Bunk bed with leisure sofa is one of the spaces saving furniture. Bunk bed with leisure sofa is a piece of furniture which it can be used as both a sofa and a bed. This wonderful flexibility of sofas convertible into beds have proved of great help those who live in small apartment and worried about the accommodation of extra guest for sleep over. They can easily be converted into beds at nights and after its purpose served it can be rearranged back to sofa. They are not difficult to be arranged and rearranged as they are flexible and comfortable enough to handle.

In this report we are going to illustrate the design and working of BUNK BED WITH LEISURE SOFA.

\section{DESIGN}

\begin{tabular}{|l|l|}
\hline Dimension(Sofa Mode) & $175 \mathrm{w}^{*} 90 \mathrm{~d} * 70 \mathrm{~h} / \mathrm{cm}$ \\
\hline Dimension(Bed Mode) & $175 \mathrm{w}^{*} 90 \mathrm{~d} * 140 \mathrm{~h} / \mathrm{cm}$ \\
\hline
\end{tabular}

Table 01: Dimension of SOFA and BED

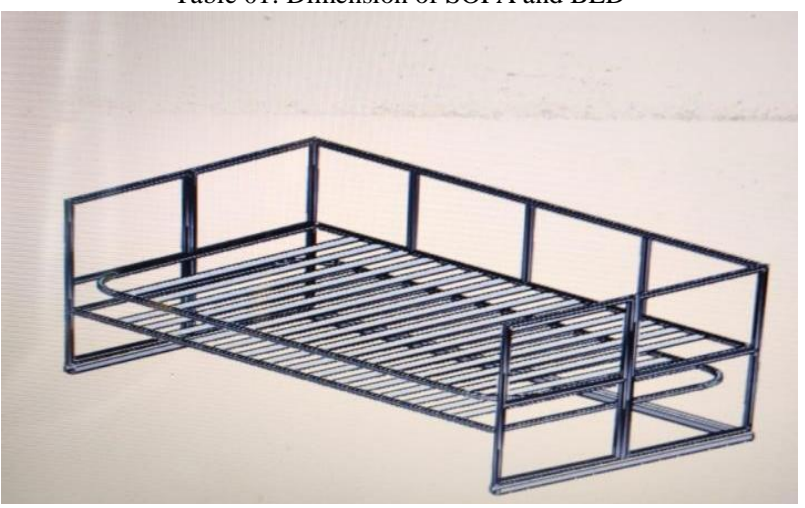

Figure 1: Design of BUNK BED with LEISURE SOFA in SOFA stage.

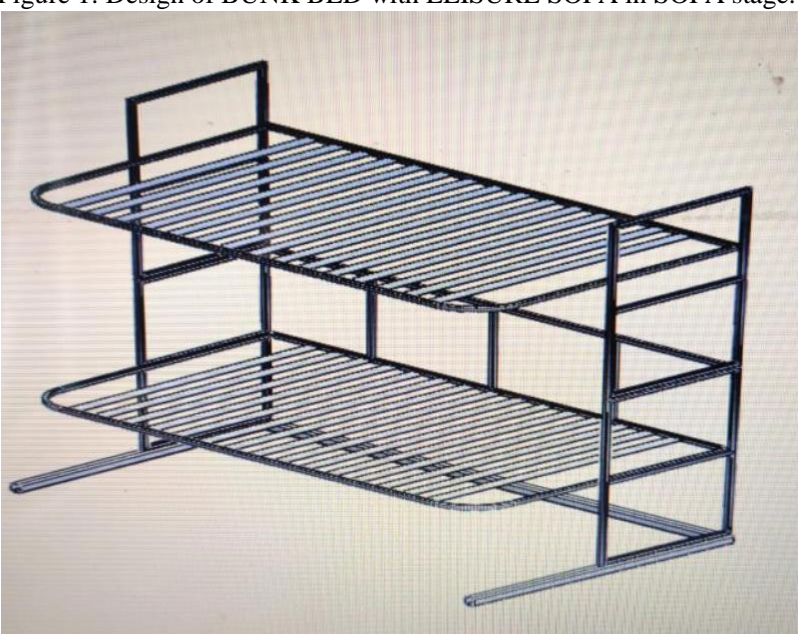

Figure 2: Design of metal frame of BUNK BED with LEISURE SOFA BUNK BED Stage. 


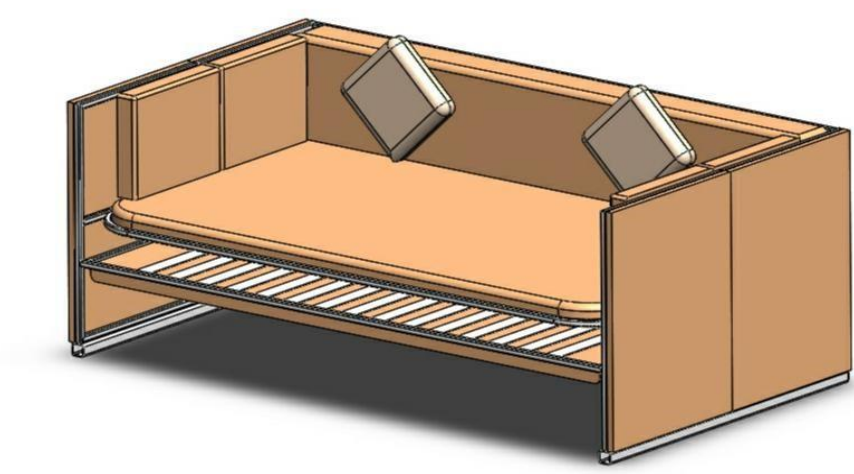

Figure 3: Design of BUNK BED WITH LEISURE SOFA (fully finished product) SOFA STAGE

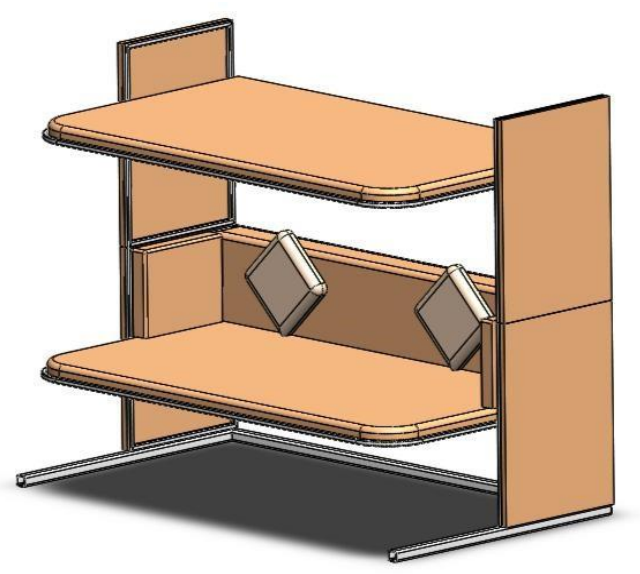

Figure 4: Design of BUNK BED with LEISURE SOFA (fully finished product) BUNK BED STAGE.

\section{MATERIAL SELECTION}

\section{A. STAINLESS STEEL}

Stainless Steels are iron-base alloys containing Chromium. Stainless steels usually contain less than $30 \% \mathrm{Cr}$ and more than $50 \%$ Fe. They attain their Stainless characteristics because of the formation of an invisible and adherent chromium-rich oxide surface film. This oxide establishes on the surface and heals itself in The presence of oxygen. Corrosion resistance and Mechanical properties are commonly the principal Factors in selecting a grade of stainless steel for a given Application There are a large number of stainless steels Produced. Corrosion resistance, physical properties, and Mechanical properties are generally among the properties Considered when selecting stainless steel for an Application. A more detailed list of selection criteria is listed below:

- Corrosion resistance

- Resistance to oxidation

- Toughness

- Cryogenic strength

- Resistance to abrasion and

- Erosion

- Resistance to galling and

- Surface finish

- Magnetic properties
- Retention of cutting edge

- Ambient strength

- Ductility

- Elevated temperature

- Strength

- Suitability for intended

- Cleaning procedures

- Stability of properties

- Thermal conductivity

- Electrical resistivity

- Suitability for intended

- Fabrication techniques

\section{APPLICATION, MARKET AND COST:-}

BUNK BED WITH LEISURE SOFA can have very wide range of applications some of them are listed below:-

\section{- HOSTELS}

Most of Hostel are designed in such a way that it should contain more number of students in least space without feeling conjugate. This will help to proper utilization of space.

\section{- FLATS AND SMALL RESIDENCE}

INDIA is one of the densest populated country in world with time area of houses is getting decrease. Most of the space in the house is covered by furniture, BUNK BED WITH LEISURE SOFA can be one optimal solution for the problem without compromise elegance of the house.

\section{- RAILWAY AND AIRPORT}

Many times due to trains and flights may be delayed for several hours, this can be provide aid of relief to the passengers who have to wait for longer hours without any stress due to improper arrangement.

- These are some examples of application of BUNK BED WITH LEISURE SOFA

Market of transforming furniture is increasing day by day. Folding Furniture Market to Reach \$13,211 Million, Globally, by 2022. According to a new report published by Allied Market Research, titled, "Folding Furniture Market Global Opportunity Analysis and Industry Forecast, 2014 2022," the global folding furniture market is expected to generate $\$ 13$ billion by 2022 The demand for folding furniture is expected to remain high during the forecast period as it is an effective alternative for traditional furniture. Hence for manufacturing at higher level can be good business

The Manufacturing cost considering all wages and material cost in India will be around $15000-20000 ₹$.

\section{CONCLUSION}

Nowadays, people tend to move to Metropolises for their greater employment Opportunities and progressive lifestyles. This Trend towards urbanization causes cities to have relatively less available free space, and also Increases the price 
of their properties. People who live in large cities can only afford small Apartments or condos and For Hostels, Hotels, Railway station and Airport this provides a good Opportunity for the development of Transformable space saving Product. This is an innovative product that has much opportunity for overheads Development and a huge potential market in metro cities for small flats and homes, Hostels, Hotels, Public Places
Lowering overhead Costs and furniture prices is another element for serious consideration.

\section{REFERENCE}

[1] https://www.prnewswire.com/news-releases/foldin g-furnituremarket-to-reach-13211-million-globally -by-2022---allied-marketresearch-613589253. 